\title{
A variação linguística nos textos literários
}

Denise Salim Santos ${ }^{1}$

Resumo: Este texto apresenta a variação linguística como recurso literário quando se faz necessário destacar os traços identitários das personagens, bem como delimitar geográfica, cultural, social e temporalmente o universo ficcional da obra literária por meio de marcas linguísticas que o caracterizem.

Palavras-chave: Níveis de linguagem. Língua literária. Língua portuguesa. Estilística.

\section{Introdução}

As relações interacionais de um indivíduo com outro, ou outros, tendem a propagar-se infinitamente, como ondas magnéticas, ao considerarmos os diferentes grupos sociais de que ele participa, expandindo-se da célula familiar até ambientes sociais mais amplos como as comunidades nacionais. Como tal, é o indivíduo quem costura as relações entre os diferentes grupos quando deles participa ativamente. Essa ideia tanto se aplica aos contatos sociais em geral como especificamente às atividades linguísticas que estreitam tais contatos quando se fala a mesma língua. Diz Herculano de Carvalho (1979, p. 295) que "dentro, pois, de qualquer comunidade linguística de maior ou menor extensão, verifica-se sempre, forçosamente, a coincidência em maior ou menor grau das técnicas linguísticas dos sujeitos que as integram”, o que não quer dizer que todos falem igualmente.

É possível observar em macro ou microcomunidades linguísticas os diversos graus de proximidade entre seus integrantes. Esses fenômenos não são, no entanto, exclusivos da linguagem. Eles são passíveis de observação no comportamento social, nos costumes, adequando-se à diversidade própria de cada região, de cada situação, enfim, do contexto onde o indivíduo se apresenta e ao qual, com dispêndio e esforço, se adapta e com ele interage.

A linguagem é uma instituição humana e, desta maneira, resulta da vida em sociedade como elemento essencial à comunicação. Ainda que suas funções básicas estejam presentes em qualquer grupo - função social, função comunicativa, função de suporte do pensamento,

\footnotetext{
${ }^{1}$ Doutora (UERJ/2008) e Mestre em Língua Portuguesa (UERJ/2000), Especialista de Educação na área de Avaliação de Desempenho Escolar. Atualmente é professora adjunta de Língua Portuguesa na UERJ/RJ e professora assistente nas Faculdades Integradas Hélio Alonso (FACHA). Integra o GT de Lexicologia, Lexicografia e Terminologia da ANPOLL. Email: d.salim@globo.com.
} 
função expressiva, função estética -, difere de comunidade para comunidade de tal forma que só funciona entre os membros de um determinado grupo que dela se utiliza no convívio social.

Para Ferdinand de Saussure (1973, p. 17), a língua, como “produto social da faculdade da linguagem é um conjunto de convenções necessárias, adotadas pelo corpo social para permitir o exercício dessa faculdade". O sistema de signos convencionais que ela coloca à disposição dos falantes de uma comunidade dada é o responsável por tornar possível a comunicação. Desde que nasce, o indivíduo é envolvido por um universo sígnico com o qual interage por meio do jogo das analogias, instintivo inicialmente, das associações e das imitações. Essa experimentação intensa com as múltiplas possibilidades comunicativas permite a formulação de mensagens que geram a troca e o convívio social baseados na língua, meio de que o falante dispõe para tal.

Dino Preti (2004, p. 28) cita Benveniste (1989, p. 282) na afirmação de que a língua é "um elemento de interação entre o indivíduo e a sociedade em que ele atua. É através dela que a realidade se transforma em signos, pela associação de significantes sonoros a significados arbitrários com os quais se processa a comunicação”. Ao considerar a interdependência entre sociedade e língua, tende-se a ver a linguagem como a forma pela qual cada comunidade linguística estrutura seu pensamento e como essas estruturas articulam linguisticamente sua realidade. Assim, admite-se a existência de uma diversidade convencionada por vários fatores de natureza externa à língua.

\section{Variação linguística}

É mais conhecida a tripartição dos níveis de fala que fazem da língua um diassistema constituído de um nível diatópico ou regional; diastrático ou sociocultural; e diafásico ou de modalidade expressiva. Tal distribuição é encontrada em Cunha (2001, p.3), Coseriu (2004, p.110), Bechara (1999, p. 37) entre outros. Cada um desses níveis de diferenciação no uso linguístico corresponde a um conceito de unidade. Assim, à relativa uniformidade no nível geográfico corresponde a uniformidade sintópica; à diferença diastrática corresponde a relativa uniformidade sinstrática ou dialeto social; e à diversidade diafásica corresponde a relativa uniformidade sinfásica.

Dino Preti, em Sociolinguística: os níveis de fala (2003, p.13-23), faz uma revisão bibliográfica interessante, apresentando reflexões de vários estudiosos do assunto que se preocupam em identificar as influências extralinguísticas que atuam sobre a língua e consequentemente sobre a linguagem, gerando a "habitual subvariedade de fala de uma dada 
comunidade, muitas vezes restrita por operação das forças sociais a representantes de um grupo étnico, religioso, econômico ou educacional específico” segundo McDavis apud Preti (2003, p. 13). Vejamos algumas delas.

Para Françoise Gadet $^{2}$, há três tipos de variação extralinguística assim discriminadas: i) geográficas, onde se posicionam as variações regionais; ii) sociológicas, que consideram as variáveis de sexo, idade, profissão, escolaridade, classe social localizadas dentro de uma mesma região, que podem determinar traços individualizados na linguagem; iii) contextuais, em que se localizam todos os fatores potencialmente capazes de gerar diferenças na linguagem empregada pelo locutor por motivos que lhe sejam externos: a clientela, o espaço-tempo em que ocorre a atividade e as relações que aproximam os interlocutores. A influência do contexto, em Gadet, vai aproximar-se do que Willian Bright apresenta como “dimensão da situação ou do contexto" (apud PRETI, 2003, p. 15).

A doutrina de Bright contempla três dimensões para a pesquisa sociolinguística quanto aos níveis de fala: i) a dimensão do emissor; ii) a dimensão do receptor; iii) a dimensão da situação ou contexto (setting). Entende-se a primeira como aquela que envolve a identidade social do emissor. Nela, as diferenças dialetais estariam ligadas à classe social à qual pertence o emissor. A segunda dimensão, que diz respeito à identidade social do receptor ou ouvinte, "seria relevante onde quer que vocabulários especiais de respeito sejam usados em se falando com superiores" (apud PRETI, 2003, p. 16). Finalmente, a terceira, que abarca todos os elementos relevantes possíveis considerados no contexto da comunicação, exceto na identidade dos interlocutores envolvidos no processo.

Não se deve perder de vista que qualquer teoria variacionista só existe em função de existência de uma unidade ou uniformidade daquilo que se denomina língua como herança do trabalho intenso para a manutenção da tradição linguística de uma comunidade - centripetismo, bem como sua renovação através dos tempos e sob circunstâncias sociais, culturais, de formas de produção que caracterizam essa mesma comunidade, centrifugismo. Ou seja, falar-se em variabilidade linguística implica a existência de uma unidade linguística em circulação dentro de um grupo de falantes.

Charles Bally defende a ideia de existirem dois pontos básicos na questão da variabilidade dos níveis de fala: i) os "estados"; ii) as formas habituais de atividade e pensamento. Estas envolvem atividades profissionais e outras atividades das mais diferentes naturezas desde as esportivas às científicas e literárias. Aqueles, os "estados", abarcam as

\footnotetext{
${ }^{2}$ A exposição sobre variação linguística, segundo Françoise Gadet, Willian Bright, Charles Bally, Marcel MacCohen, Gleason e Claire Lefebvre se baseia em PRETI, D. (2003).
} 
condições pré-existentes aos indivíduos como cultura, classe social a que pertencem, orientação religiosa, ética e moral. Também o ócio aqui se incluiria, pois, de alguma forma, ele permite a aproximação de indivíduos, como o jogo de cartas ou de damas na pracinha. Percebese que o meio, na concepção de Bally, não faz referência aos limites geográficos, mas antes à superposição desses diversos meios em que se encontra o mesmo indivíduo.

Marcel MacCohen confirma que diferenças de origem, profissão, nível de vida e religião aparecem reunidas como fatores que acarretam a diversidade no uso da língua, e Gleason aponta o contexto social do enunciado específico, a posição social do locutor, sua origem geográfica e sua idade como variáveis linguísticas.

Claire Lefebvre apresenta outras dimensões para a variação linguística: i) dimensão geográfica associada às regiões; ii) dimensão histórica associada às diferenças caracterizadas dos diversos estágios de evolução de uma língua; iii) dimensão estilística, associada às situações nas quais a língua é utilizada. Para estas dimensões, Lefebvre abre um leque de termos de referência, a saber: "níveis de língua", "registros", "estilo", "código", "variedade padrão" ou "língua não padrão", "língua formal" ou "língua familiar" etc.

Herculano de Carvalho também é referido na pesquisa de Preti, mas nos reportamos a seu livro Teoria da Linguagem: natureza do fenômeno linguístico e a análise das línguas (1979, p. 291-316) para registrar sua visão sobre o assunto. Carvalho parte da consideração da existência de uma "unidade idiomática" na qual estão contidos os idioletos individuais e intraindividuais (que chama de normas de estilo) e os idiomas ligados por entidades idiomáticas homogêneas porque sistemáticas, sujeitas à mesma norma, que podem chegar a outra unidade não tão homogênea e até bem individualizada a que denomina língua, abarcando aí, "os modos de falar, todas as técnicas linguísticas - variedades interindividuais, geográficas, sociais e históricas por vezes muito diferentes entre si, faladas por diversos indivíduos de uma comunidade linguística uma" (1979, p. 326), unicidade fruto da consciência dos falantes da língua para além das diversidades do falar.

Para Carvalho, tratando-se de variedade linguística, há dois fatores que contribuem significativamente: os fatores geográficos e os fatores socioculturais. No primeiro - variedades geográficas, regionais ou locais - encontram-se os dialetos e os falares fixados através de gerações sob a influência cultural, política e econômica de cada região sobre seus falantes. Sob o segundo fator - o sociocultural - agasalha-se a ideia de que, numa mesma região geográfica, encontram-se técnicas linguísticas diferenciadas, considerando-se que aqueles que "ali nasceram e se criaram não falam todos da mesma maneira" (CARVALHO, 1979, p. 299), pois espelham o ambiente mais íntimo onde tiveram os primeiros contatos com a língua que usam 
em seus atos de fala, assim como os traços culturais de seus núcleos primários. É certo que há contatos mais ou menos estreitos com outras comunidades, mas não suficientemente fortes para apagar de vez o produto da relação que há entre os integrantes de um mesmo grupo social.

Outro par de variação é o que nos fala do estilo coloquial e do estilo refletido (reflectido). Cada uma dessas modalidades de uso da língua tem suas características próprias. Herculano de Carvalho (1979, p. 302) comenta as variedades estilísticas, ressaltando o caráter individual, pois um mesmo sujeito falante é capaz de usar técnicas linguísticas diferenciadas em função da adequação necessária "para finalidades específicas, para satisfação das necessidades cognitivas e manifestivas próprias de cada uma de suas atividades linguísticas".

Ainda citando Carvalho (1979, p. 304-6), vejam-se as características do estilo coloquial:

1) Os conteúdos cognoscitivos nele exteriorizado são relativamente pobres visto serem determinados pelas necessidades vitais imediatas do dia a dia na sua mais simples expressão. 2) Essa exteriorização destina-se a um feito eminentemente prático e sobretudo imediato. Nestes actos da linguagem quotidiana as finalidades realizadas são de facto, antes de mais nada, de natureza apelativa e também expressiva (mas geralmente não estética) na sua forma mais elementar [...]. 3) Constatamos que estes momentos de actividade se realizam com um mínimo de consciência da escolha das formas linguísticas usadas e com um mínimo de adesão consciente ao sistema da língua.

A seguir, as características do estilo refletido:

1) Os conteúdos cognoscitivos aí manifestados são relativamente ricos e complexos, pelo facto de serem determinados por uma atividade intelectual, emotiva e mesmo volitiva dirigida por uma satisfação, não meras necessidades quotidianas e em grande parte materiais, mas de exigências espirituais mais elevadas: o conhecer especulativo e estético, a actuação social transcendendo o âmbito do indivíduo.2) O efeito desta exteriorização pode não ser de natureza prática e sobretudo não tem que ser imediato. [...] mesmo nesses atos em que predomina a volição e, portanto, a função apelativa, o efeito nunca é imediato [...], (o estilo refletido) se destina a actuar no comportamento social dos ouvintes, não ali e naquele instante mas, por assim dizer, a longo prazo [...]. 3) Finalmente esse actos verbais são realizados com um máximo de consciência das formas linguísticas usadas e com o máximo de adesão ao sistema da língua.[...]. Aqui o sujeito falante preocupa-se em não errar, em não "atropelar a gramática", em se exprimir "com correção e elegância". 
Também são consideradas pelo linguista português as variedades sincrônicas, fenômenos de variação que se deixam observar no mesmo recorte temporal, e as diacrônicas, onde repousam a tradição, os planos temporais de uma língua histórica.

O estudo da variação linguística enfocando o "contínuo da urbanização", o "contínuo da oralidade-letramento" e o "contínuo do monitoramento estilístico" é apresentado por Stella Maris Bortoni-Ricardo (2004). A existência de domínios sociais - família, escola, igreja possibilita que as pessoas interajam, assumindo diferentes papéis sociais construídos no processo da interação humana, com seu conjunto de obrigações e direitos definidos por normas socioculturais.

Nessas circunstâncias também a linguagem é elemento fundamental para construir e reforçar os papéis sociais peculiares a cada domínio. Diz a pesquisadora que as diferenças encontradas são devidas à necessidade de monitoramento do uso da língua em função dos eventos e do nível de formalidade onde é usada. Fatores históricos também interferem. Conforme Bortoni-Ricardo (2004, p. 34):

No Brasil, os falares das cidades litorâneas, que foram sendo criadas ao longo dos séculos XVI e XVII[...] sempre tiveram mais prestígio que os falares das comunidades interioranas. Isto se explica porque as cidades brasileiras que estão voltadas para a Europa receberam um contingente muito grande de portugueses nos três primeiros séculos de colonização e desenvolveram falares próximos dos falares lusitanos. Observemos também que, até 1960, a capital do Brasil se situava no litoral. [...]. É natural que a cidade sede do governo tenha mais poder político e prestígio, e esse prestígio acaba por se transferir ao dialeto da região.

Bortoni-Ricardo (2004, p. 34) acrescenta a rede social do falante como mais um componente que contribui para as variações, uma vez que a pluralidade de pessoas envolvidas na interação acrescenta características outras ao repertório do falante. Assim, os atributos (idade, sexo, status, nível de escolarização etc.) associados aos fatores funcionais existentes na dinâmica das interações possibilitam a construção do repertório sociolinguístico do falante, não esquecendo que os fatores estruturais da própria língua (fonologia, morfologia, sintaxe) estão presentes nessas considerações.

Das três linhas de estudo propostas, interessa mais de perto aquela que trata da monitoração do estilo, que trabalha com a existência de uma linha em que em um extremo se encontram os falares rurais mais isolados e, em outro, os falares urbanos, marcados pela ação significativa dos agentes padronizadores: imprensa, escola, igreja, repartições públicas, 
produção literária com o predomínio do estilo monitorado da língua, tanto na escrita quanto na fala.

Um dos fatores relevantes nos estudos variacionistas diz respeito às escolhas $\mathrm{e}$ adequações feitas pelo falante em relação às situações e às finalidades do uso linguístico. A esse trabalho de seleção/adequação denomina-se monitoramento. Considera-se estilo monitorado aquele que demanda do falante maior cuidado com o uso das formas da língua em função de fatores como: dependência da situação de uso; interlocutor e sua relação com o poder; desejo de causar boa impressão; grau de formalidade do assunto. Em linhas gerais, a monitoração estilística consiste no esforço feito pelo falante ao aplicar sua competência comunicativa na adequação da fala aos papéis sociais que assume. Ressalte-se que esse cuidado existe na interação interpessoal e também na intrapessoal (escolhas de caráter pessoal que marcam o estilo de fala de cada indivíduo), em que o mesmo falante alterna estilos monitorados e não monitorados, quando a situação assim o exige.

Luis Carlos Travaglia, em Gramática e interação: uma proposta para o ensino de gramática no $1^{\circ}$ e $2^{\circ}$ graus (2000, p. 41-66), apresenta de maneira bastante didática as dimensões das variedades da língua. Em linhas gerais sua distribuição é semelhante às demais, apenas preferindo o termo dialeto para as variantes na dimensão regional, geográfica ou local. Segundo ele, nos dialetos, as marcas diferenciais são mais nítidas nos campos da fonética e do léxico, por estarem os falantes "contidos" num espaço delimitado política, econômica, culturalmente e serem fruto das influências que cada região sofreu em sua formação.

Na dimensão da variedade social, Travaglia (2000, p. 45) acentua a influência da classe social a que pertence o falante na produção de seus atos de fala. A classe social aqui está diretamente ligada às atividades profissionais. Diz ele que "é por isso que se consideram como variedades dialetais de natureza social os jargões profissionais ou de determinadas classes sociais bem definidas como grupos (linguagem dos artistas, professores, médicos, mecânicos, estivadores, dos marginais)", embora, a seguir, ele complemente com "classe alta", "favelados", "gíria" etc.

O que existe nessa dimensão são superposições e matizes de usos que estariam mais ligados a graus maiores ou menores de formalismo no uso da língua. Destaca-se aqui o papel da língua como identificação grupal, ou seja, o grupo de falantes ganha identidade pela linguagem que usa. Quanto aos dialetos da dimensão da geração, interessam as observações que ressaltam variação histórica e não de idade, o que liga essa dimensão à variação diacrônica. Para Travaglia (2000, p. 48), “as variações históricas existem e são percebidas na língua escrita, por causa do registro que as faz permanecer no tempo". 
Para este estudo, é relevante o que o linguista apresenta sobre as variações de registro, que se assentam em três tipos: graus de formalismo, de modo e de sintonia. Travaglia propõe graus de formalismo, escalonados para mais ou para menos, que levem em conta o cuidado com o uso dos fatos da língua, assim como a variedade de recursos empregados na construção de enunciados. Quanto à variação de modo, explicita a modalidade escrita e a modalidade oral. Cada um desses modos de produção comporta um conjunto próprio de graus de formalismo.

Reproduz-se aqui o quadro de escalonamento dos graus de formalismo proposto pelo linguista por ser importante para a observação de como essas variações são materializadas no universo literário, por exemplo (TRAVAGLIA, 2000, p. 54):

\section{Língua falada \\ oratório \\ formal (planejado) \\ coloquial \\ coloquial distenso \\ familiar (ou íntimo)}

\author{
Língua escrita \\ hiperformal \\ formal \\ semiformal \\ informal \\ pessoal
}

Na dimensão de registro ou sintonia, a variação irá ocorrer toda vez que o falante se preocupar em ajustar sua fala às condições de seu ouvinte, levando em conta o status, a tecnicidade, a cortesia e a norma. O status, de modo geral, está relacionado à variante de grau de formalismo. A tecnicidade leva em conta o grau de informação que o ouvinte tem sobre o assunto tratado pelo falante. A variação de cortesia está ligada ao grau de polidez maior ou menor, de acordo com os participantes da interlocução, oscilando entre um alto grau de formalismo até as expressões desonrosas ou de baixo calão e as formas de atenuação como o eufemismo. A variação na dimensão da norma se adapta à expectativa do interlocutor, ou seja, o locutor falará a língua da assistência.

O trabalho elaborado quanto à fonética, à sintaxe e, principalmente ao léxico, melhor dizendo, ao vocabulário empregado em um texto literário pode nos oferecer oportunidade singular para observar as considerações feitas aqui com relação aos fenômenos de variabilidade linguística, tanto na perspectiva da interação intergrupal como na da relação intrapessoal (monitoramento ou estilo).

As sementes de uma literatura caracteristicamente brasileira, levadas pelos ventos nacionalistas do Romantismo, fecundaram o solo da inquietação modernista e ali germinaram, dando-nos uma paisagem literária bastante variada, cujos frutos saborosos apreciamos na literatura brasileira contemporânea. Uma definição oficial, acadêmica, do que seja língua 
literária ainda é tema que ocupa os estudiosos. Persistindo a polêmica, é porque ainda há espaço para alguma reflexão sobre o assunto.

Não seria o caso, por exemplo, de serem levadas em consideração as condições de uso, ou melhor dizendo, as circunstâncias em que a língua se realiza a partir de uma série de condicionantes necessariamente impostas ao escritor, em face do projeto elaborado, pelo menos inicialmente, de uma obra que se candidata ao status de obra literária? O fato de ser uma produção na modalidade escrita não o sobrecarregaria de certos cuidados com técnicas e artifícios adequados para trabalhar com variantes necessárias dessa mesma língua quando pretendesse, principalmente, diminuir a distância entre a língua escrita e a língua falada num trabalho de monitoramento estilístico?

Ainda mais uma ponderação: este autor, certamente, é alguém que convive com textos de qualidade reconhecida, conhece e admira as produções clássicas da literatura, e até as tem como modelos, mantendo contato permanente com o padrão culto (ou cultuado) da língua. A consequência dessa relação tão íntima não seria a internalização cada vez mais forte desse padrão, numa atitude de reverência à tradição da língua portuguesa que, fatalmente, iremos encontrar refletida, em algum momento, nos seus escritos?

Do romancista João Ubaldo Ribeiro é esta declaração feita à Revista Caderno Literário (1999, p. 49):

[...] presto muita atenção na fala dos cariocas para quando escrever em carioquês para não errar a mão. Carioca diz 'Dá um cafezinho pra mim'. Na Bahia se diz 'Me dê'. Aqui soa autoritário. Os cariocas falam: 'A Fulana, o Beltrano'. Isso é um tapa no ouvido do nordestino. No Nordeste todo mundo fala direto 'Fulana, Beltrano', sem usar o artigo. Quando vou para Itaparica, entro na língua de lá, 'como' todas as proparoxítonas. Falo padre Ciço, não padre Cícero - Cícero é só para gente culta.

A consciência linguística do escritor, em toda a sua extensão, é demonstrada nessa passagem. Quando há necessidade, recorre à variante culta da língua. Quando a intenção é dar a cor local, usa a variante adequada, do que é possível deduzir que, na literatura, também pode ocorrer a penetração, sorrateira ou não, da informalidade, do coloquial, da variante popular como já acontecia nas obras clássicas da Antiguidade.

Falar-se em modos e usos da língua para fins literários pode soar como artificialismo porque resultam de um ato de escolha deliberada do autor na busca da melhor maneira do dizer, do descrever, do narrar o que vê, o que sente ou imagina na pretensão de criar um mundo 
real dentro da ficção. De fato, não deixa de ser um artificialismo, mas um artificialismo expressivo, provocador de halos especiais de criatividade em torno daquilo que seria natural.

Tais reflexões, a nosso ver, facilitam ao artista da palavra construir um texto em que a língua como diassistema prova a sua constante revitalização, a partir de cada uma das possibilidades de realização, condicionadas por uma série de fatores que, em verdade, transformam a língua em discurso, entendendo-se discurso como necessariamente um acontecimento protagonizado por um enunciador e um ou mais destinatários numa situação que inclui o momento histórico e o contexto, segundo Azeredo (2000, p. 34-5).

\section{Repensando a língua no texto literário}

No caso da obra literária, temos uma das possíveis ocorrências de um discurso planejado, em que "o enunciador tem a palavra e dela dispõe controlando o desenvolvimento do seu texto segundo sua vontade", (AZEREDO, 2000, p. 35), embora, tal como ocorre na descrição do fazer literário, digam alguns escritores que as personagens de seus romances, por exemplo, determinam os seus próprios destinos, afastando-se muitas vezes do projeto inicial da obra.

Rajagopalan (2003, p. 117) defende que a obra de ficção, para ser entendida, não dispensará a noção de "fingimento"; ou seja, o autor de uma obra de ficção finge, voluntariamente, quando está executando os atos de fala que compõem a obra. Lembrando Searle, o linguista complementa: "a possibilidade de fingimento se deve à existência de um conjunto de convenções que suspendem a operação normal das regras que relacionam atos ilocucionários e o mundo", ou seja, o escritor finge que relata um determinado ato real discursivo e o leitor entra no universo do fingimento. Para que este contrato "fingidor" se concretize, a narrativa de histórias se transforma num jogo de linguagem especial de que participam o escritor e o leitor.

Para apresentarmos praticamente a questão da variação linguística no fazer literário, selecionamos dois fragmentos de textos literários importantes de nossa literatura. O primeiro é do poema Y-Juca-Pirama, de Gonçalves Dias, composto em 1851, peça literária reconhecida como monumento representante do indianismo no movimento romântico no Brasil. O segundo, selecionado no romance Feitiço da ilha do Pavão, de João Ubaldo Ribeiro (1997):

1 - Tu choraste em presença da morte?

Na presença de estranhos choraste?

Não descende o cobarde do forte;

Pois choraste, meu filho não és! 
Possas tu, descendente maldito

De uma tribo de nobres guerreiros,

Implorando cruéis forasteiros,

Seres presa de vis Aimorés.

"Um amigo não tenhas piedoso

Que o teu corpo na terra embalsame,

Pondo em vaso d' argila cuidoso

Arco e frecha e tacape a teus pés!

Sê maldito, e sozinho na terra;

Pois que a tanta vileza chegaste,

Que em presença da morte choraste,

Tu, cobarde, meu filho não és."

(Y-Juca Pirama. Gonçalves Dias. Poesia completa, 1959)

2 - Cadê tendente? Cadê Dão Filipe de Meulo Furutado? Cadê condenado pecador, tendente estrumo?. UÁ! UÁ! Índio mata, índio dá carne de branco postadinha pra guará, pra raposa, pra tatu, pra aribu, pra siri e pra mecê atecuri, na terra, no vento e na maré! Índio pega toda gente e mata a dentada arrum-arrum, creque-creque, ramo-ramo, racha cabeça, bebe sangue na coité, tuque-tuque ! Curuí-curuê, é com vossimececê (RIBEIRO, J. U. O feitiço da ilha do Pavão, 1997, p. 36).

Considerando que os dois discursos apontados pertencem a figuras da mesma etnia e cada um a seu modo representa o índio na formação da identidade brasileira, comparemos as formações discursivas. Nos dois fragmentos está presente a imagem do índio que não se abate diante do medo ou diante do poder opressor. No entanto, este traço comum se faz representar por discursos bastante diversos, uma vez que as estéticas que os orientam também são diferentes.

A estética romântica de Gonçalves Dias vê o índio como um ser exótico, idealizado pelo movimento romântico e a ele empresta uma linguagem tipicamente clássica, à moda europeia. É um poema com características épicas: ritmo próprio, perfeita utilização dos vários recursos de métrica, musicalidade e ritmo, além do herói idealizado. Quanto à construção do discurso poético, encontramos uma língua exuberante, clássica, bastante ligada à influência do português europeu, marca de variação diatópica ou geográfica, além da escolha pelo registro do uso formal culto: um respeito ao cânone gramatical, denotado pelo uso da $2^{\mathrm{a}}$ pessoa do singular (tuteamento), no imperativo; pela inversão dos elementos frasais, que soam artificiais considerando tratar-se da fala ameríndia em discurso direto e, ainda, pela presença de palavras como "cobarde" e "frecha", resquício etimológico de palavras contemporaneamente usadas: covarde e flecha. 
À leitura do poema, dir-se-ia que, àquela altura da História, os índios do Brasil já dominavam o mais escorreito português. Com relação ao léxico, de elemento não lusitano, poucos são os termos que aparecem em todo o poema (taba, maracás, enduape, cauim, muçurana, embira, manitôs, Tupã, tapuias, iverapeme). As demais palavras pertencem ao repertório do português culto da época, o que permitiria uma leitura de valorização mítica dos primeiros habitantes do Brasil.

Já no segundo fragmento, veem-se manifestações linguísticas que marcam uma ampla atitude transgressora mais aceita na literatura contemporânea não em relação ao caráter do selvagem brasileiro em si, mas na apresentação exagerada, caricatural do que seria o falar indígena em processo de transculturação natural, resultante do contato de dois estratos tão diferentes: a língua do branco europeu e a língua do indígena brasileiro.

É fácil observar que o romancista João Ubaldo Ribeiro exacerba esse "esforço" de aquisição e ao mesmo tempo de nivelamento com a língua do dominador representante do poder instituído, usando recursos que, à época de Gonçalves Dias, não seriam aceitos, certamente, no exercício de uma língua literária, mas que, graças ao movimento modernista, tornaram-se viáveis dentro da literatura. A luta para romper os padrões vigentes e abrir novos caminhos liberava outras possibilidades para a produção literária nacional. Nas palavras de Silvio Elia (1975, p. 32), o movimento romântico no Brasil teve grande repercussão: "trouxenos a independência literária, criou valores permanentes em nossa modesta, mas já ilustre galeria de homens de letras, permitiu uma adequação mais sincera entre a língua escrita e a língua falada" (Grifo nosso).

As estratégias de construção do discurso da personagem ubaldiana, O Tantanhengá, apelam para as transgressões, para os desvios de um padrão de língua formal, mas com o aval da própria história da língua; ou seja, os recursos empregados na construção dos "estranhos vocábulos" já foram exaustivamente estudados pelas gramáticas históricas e normativas da língua portuguesa quer na perspectiva sincrônica, quer na perspectiva diacrônica.

O discurso de Tantanhengá vem crivado de fenômenos fonéticos recorrentes na fala comum, que chegam até o leitor pelas alterações gráficas no significante das palavras, na tentativa de reproduzir "fielmente" o modo de a personagem materializar a língua, como as ocorrências de assimilação regressiva em Filipe por Felipe; epêntese em Meulo por Melo, ou em Furutado por Furtado; aférese em tendente por intendente; síncope em pra por para.

Quanto à palavra aribu, os dicionários gerais ou especializados listados nas consultados não fazem nenhuma referência à pronúncia eleita pelo escritor. Fecha-se, então, o circuito de um discurso eivado de humor, desconstrutor por excelência da autoridade instituída do 
intendente Felipe de Melo Furtado (ele será comida de aribu e não de urubu), ao mesmo tempo em que a caricatura da fala da personagem indígena distancia-a de sua língua primeira (urubu é vocábulo tupinambá) e também a exclui do domínio completo da língua do dominador.

No plano da morfologia, aparece o interrogativo cadê, construção do português do Brasil. Segundo Fernandes (2000, p.110), há outras variantes de uso desse interrogativo resultantes da contração de toda uma frase que éfeito de ou da locução prepositiva "que é de": "quede".

Dos processos de formação de palavras, destacam-se a composição e a derivação sufixal. Para este caso, temos o uso da forma diminutiva, do adjetivo postadinha, com fins intensificadores. Quanto à composição, as onomatopeias que ocorrem são relevantes para completar a cena de canibalismo ali sugerida. $O$ escritor sente necessidade de imitar objetivamente e jogar com a impressão que elas possam causar no leitor a partir do efeito sonoro das formas arrum-arrum, creque-creque, ramo-ramo, tuque-tuque, todas neológicas e ligadas semanticamente à sensação auditiva das diferentes etapas do ato de comer ou beber, como se não fossem suficientes os sintagmas "matar a dentadas" ou "beber o sangue".

No plano lexical, a legitimação da cultura indígena se confirma pela seleção vocabular, principalmente em relação aos substantivos utilizados na nomeação dos animais, todos de origem Tupi: guará (garça), siri, tatu; na nomeação de objetos como coité. Com relação aos vocábulos curuí-curuê e atecuri, que supusemos ser termo do Tupi, não encontramos no Vocabulário Tupi-Guarani Português de Francisco Silveira Bueno (1981) qualquer referência, quer fosse da forma composta, quer das palavras isoladamente, o que nos faz pensar que o escritor criou, na verdade, uma camada sonora que desse ritmo à fala que termina com vossimicecê, produzindo uma espécie de eco. Ou, quem sabe, apenas uma brincadeira com as palavras para divertir o leitor. São hipóteses de leitura, apenas.

Destoa nessa relação a palavra raposa, cujo correspondente em tupi é gambá. O escritor, no entanto, preferiu o primeiro termo que, segundo o Dicionário Houaiss (2001), tem origem controversa, datação do século XIII e nomeia um animal característico do Hemisfério Norte. Traço da cultura europeia intencionalmente apresentado? Deslize do escritor? Parece-nos que vai interessar ao plano da obra dar pistas de que o índio, habitante da ilha do Pavão, já internalizou unidades do léxico do dominador europeu.

No texto aparecem duas formas do mesmo pronome de tratamento: mecê e vossimececê. A primeira é um brasileirismo informal oriundo da evolução do pronome de tratamento vossa mercê, conforme registrado por Amadeu Amaral, em seu Dialeto Caipira (1976, p.153), do qual transcrevemos: "MECÊ, pron. de tratamento da $3^{\mathrm{a}}$ pess. II De vossa mercê, que deu toda 
uma série de formas, nem sempre usadas, indiferentemente, umas pelas outras: vossuncê, vansuncê, vamicê, vancê, vacê, ocê, mecê. [...]”.

Amaral (1976, p. 153) comenta que a forma mecê era "mais usada pelos pretos que por outra qualquer gente". No texto de Ubaldo, também o índio usa esta forma, marcando mais a característica do uso da forma popular como marca de oralidade, que a questão étnica. Nos dicionários gerais são registradas ainda outras formações ao longo da evolução desse pronome de tratamento: "vossancê" (1665), "vossê" (1721), mas não há referência à forma "mecê" empregada no texto.

Quanto ao plano da sintaxe, mantém-se no geral a tradição do português de Portugal à exceção de uma construção frasal na ordem direta e curta, traços de oralidade levados ao texto literário.

Voltando ao índio idealizado de Gonçalves Dias, observamos que ele é dono do seu discurso, pela presença da primeira pessoa, denotando o apagamento do pronome de primeira pessoa, uso indicado por algumas gramáticas normativas por já trazer o verbo a marca desinencial de pessoa. Este uso é característico até os dias de hoje do português europeu. Já no português brasileiro, opta-se pela presença do pronome reto na função subjetiva.

Quanto à discursividade de Tantanhangá, o sujeito se apresenta em $3^{\mathrm{a}}$ pessoa, pelo emprego da palavra índio, trazendo ao discurso não o individual, mas a coletividade indígena. Do índio, ainda não fora reconhecida sua identidade. Como uma criança aprendendo a falar, não reconhece ou emprega o sujeito pronominal de $1^{\mathrm{a}}$ pessoa do singular em sua fala.

Para provocar mais uma reflexão, em $O$ Guarani, de José de Alencar, (s/d, p. 157) o herói Peri, quando lhe é dada voz, refere-se a si mesmo por seu nome. Embora o discurso permaneça em $3^{\text {a }}$ pessoa, ele se individualiza:

- Assim, disse Álvaro sorrindo, tu só me amas porque pensas em que Cecília me quer? Disse o moço.

- Peri só ama o que a senhora ama porque só ama a senhora neste mundo: porque ela deixou sua mãe, seus irmãos e a terra onde nasceu.

- Mas se Cecília não me quisesse como julgas?

- Peri faria o mesmo que o dia e a noite: passaria sem te ver.

As formações discursivas obedecem ao mesmo padrão do uso culto da língua tanto na fala de Peri quanto na de Álvaro, inclusive com o emprego impecável da segunda pessoa do singular na interlocução das personagens. 


\section{Conclusão}

Do que foi visto, conclui-se que não é possível falar em variação linguística sem se considerarem as circunstâncias geográficas, sociais e culturais em que o falante está imerso. Também não é possível abandonar alguns itens da interação através da palavra: adequação ao ouvinte, ao assunto, enfim à situação de uso. A necessidade de comunicação, de interação pela linguagem impõem ao falante o exercício de várias técnicas enunciativas, ou seja, o monitoramento e sua fala, para que, efetivamente, ele seja um participante ativo dentro de seu grupo social e fora dele.

Demonstrou-se ao longo deste artigo que o uso literário da língua, uma das variantes linguísticas, está preso ao compromisso do escritor em conhecer profundamente a língua portuguesa em suas variedades de uso, dando identidade linguística às personagens, atualizando sempre que necessário seu instrumento de trabalho. Com versatilidade e talento, gravam os artistas da palavra em suas obras o respeito aos mais diversificados usos da língua, incluindo-se aqui também a variante formal da língua, mas permitindo claramente ou de maneira sutil a presença de outras falas representantes dos diferentes grupos sociais, ou seja, a fala do povo brasileiro na literatura.

\section{Referências bibliográficas:}

AMARAL, A. $O$ dialeto caipira: gramática-vocabulário. 3 . ed. São Paulo: HUCITEC/SCCT/ESP, 1976.

AZEREDO, J. C. Fundamentos de gramática do português. Rio de Janeiro: Jorge Zahar, 2000.

BECHARA, E. Moderna gramática portuguesa. 37. ed. Rio de Janeiro: Lucerna, 1999.

BORTONI-RICARDO, S. M. Educação em língua materna: a sociolinguística na sala de aula. São Paulo: Parábola, 2004.

CARVALHO, J. G. H. Teoria da linguagem: natureza do fenômeno linguístico e a análise das línguas. V. I. Coimbra: Atlântida, 1979.

COSERIU, E. Lições de linguística geral. Rio de Janeiro: Ao Livro Técnico, 2004.

CUNHA, C. \& CINTRA, L. A nova gramática do português contemporâneo. 3. ed. Rio de Janeiro: Nova Fronteira, 2001.

FERREIRA, A. B. H. Novo Aurélio Século XXI: o dicionário da língua portuguesa. 3. ed. rev. Rio de Janeiro: Nova Fronteira, 1999. 
HOUAISS, A. Dicionário Houaiss da Língua Portuguesa. Rio de Janeiro: Objetiva, 2001.

PRETI, Dino. Sociolinguística: os níveis de fala. 9. ed. São Paulo: EdUSP, 2003.

PROENÇA FILHO, D. Novas seletas: João Ubaldo Ribeiro. Rio de Janeiro: Nova Fronteira, 2004.

RAJAGOPALAN, K. Por uma linguística crítica: linguagem, identidade e a questão ética. São Paulo: Parábola Editorial, 2003.

SAUSSURE, F. de. Curso de linguística geral. 5. ed. São Paulo: Cultrix, 1973.

TRAVAGLIA, L. C. Gramática e interação: uma proposta para o ensino de gramática no $1^{\circ} \mathrm{e}$ $2^{\circ}$ graus. 5. ed. São Paulo: Cortez, 2000.

\section{Linguistic variation in literary texts}

Abstract: This article proposes a reflection on linguistic variation as a resource for literary writing in a moment that is necessary to highlight traces of identity, as well as to emphasize the fictional universe of the literary work in geographic, cultural, social and temporal terms, according to the linguistic theories that characterize this universe.

Key words: Linguistic variation. Levels of language. Literary language. Portuguese language. Stylistics. 